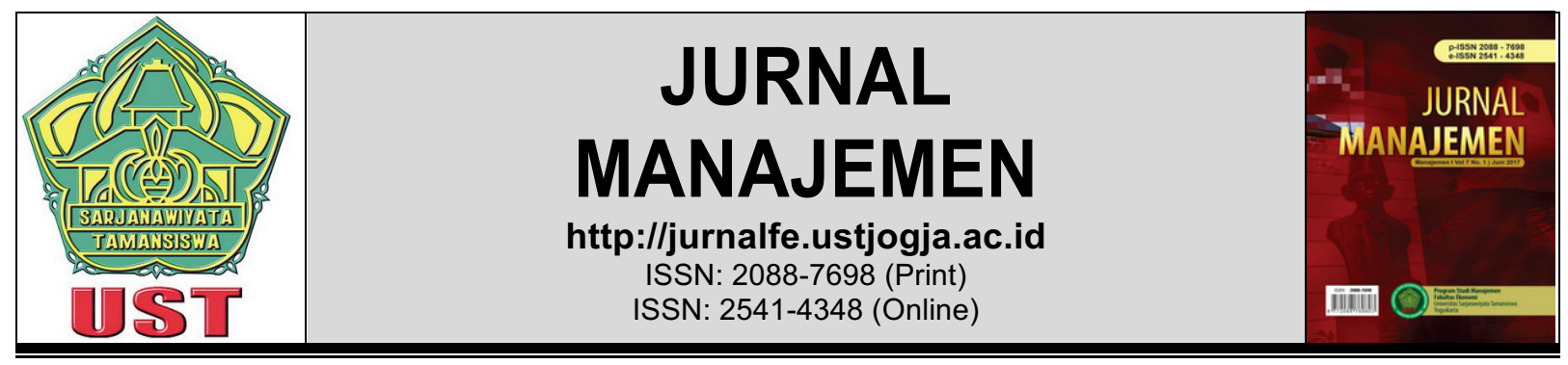

\title{
PENGARUH GAYA KEPEMIMPINAN TRANSFORMASIONAL TERHADAP KETERLIBATAN KERJA KARYAWAN DENGAN ORIENTASI BUDAYA INDIVIDU SEBAGAI VARIABEL PEMODERASI
}

\section{Daniel Joel Immanuel Kairupan}

\author{
STIE YKPN
}

Korespondensi: danielkairupan@gmail.com

\begin{tabular}{ll}
\hline Informasi Naskah & \multicolumn{1}{c}{ Abstrak } \\
\hline Diterima: & In the process of managing human resources and to realize good \\
3 Oktober 2017 & organizational performance hence required adequate leadership. \\
Revisi: & Because leadership is one of the most dominant factors in \\
23 Oktober 2017 & determining value and influencing culture within the organization. \\
Terbit: & One of the existing the leadership styles is transformational \\
1 Desember 2017 & leadership. This leadership believed to affect the level of employee \\
\hline Kata Kunci: & engagement. In addition, employee job involvement in work is also \\
Transformational & influenced by the orientation of individual cultures. \\
Leadership, Job & This researce aims to examine the effect of transformational \\
Involvement, Power & leadership on employee engagement. It also examines the effects \\
Ranges, Collectivism, & of power ranges, collectivism, feminism, and the avoidance of \\
Masculinity, Avoidance of & uncertainty in moderating between in the influence of \\
Uncertainty. & transformational leadership and employee engagement. \\
& The results show that there is influence of transformational \\
& leadership towards employee job involvement. Uncertainty \\
& avoidance is so found to positively moderate the influence of \\
& transformational leadership on employee job involvement. \\
& Meanwhile the range of power, collectivism, masculinity is not \\
proven to moderate the relationship.
\end{tabular}

\section{PENDAHULUAN}

Perekonomian global secara tidak langsung telah mengubah peta persaingan antar perusahaan, baik yang berskala nasional ataupun multinasional. Ketika sebuah negara berani membuka diri untuk bersaing dengan negara lain, secara tidak langsung mereka juga telah membuka kesempatan perusahaan lokal untuk bersaing dengan perusahaan yang berada diluar negeri. Untuk melakukan kegiatan operasionalnya, setiap membutuhkan sumber daya manusia 
yang memiliki kualitas dan kompetensi yang unggul.

Sumber daya manusia atau karyawan merupakan suatu komponen yang sangat vital bagi sebuah perusahaan. Mereka menjadi pelaksana utama bagi sebuah aktivitas manajerial dan operasional. Faktor penunjang sebuah perusahaan tidak akan berjalan dengan baik apabila tidak dilakukan dengan baik oleh sumber daya manusia yang dimiliki.

Dalam proses pengelolaan sumber daya manusia dan untuk mewujudkan kinerja organisasi yang tepat dan baik maka diperlukan kepemimpinan yang memadai. Sehingga kepemimpinan merupakan salah satu faktor yang paling dominan dalam menentukan nilai dan mempengaruhi budaya dalam organisasi. Kepemimpinan harus mampu memotivasi atau memberi semangat kepada para bawahannya, dalam hal ini adalah sumber daya manusia, dengan cara menginspirasi atau memotivasi mereka untuk dapat bekerja dengan maksimal. Berdasarkan teori yang ada, gaya kepemimpinan terbagi menjadi gaya kepemimpinan transaksional dan transformasional.

Visi dari pemimpin transaksional didasarkan pada hubungan antara pemimpin dan pengikutnya. Hubungan antara pemimpin dan karyawan hanyalah sebatas rantai transaksi. Akar dari gaya kepemimpinan ini adalah pemberian hadiah dan pemberian penalti atau hukuman (Odumeru dan Ogbonna., 2013). Sementara pemimpin transformasional selalu melakukan penanganan masalah dengan pendekatan khusus. Sehingga peran pemimpin transformasional tidak hanya memberikan perintah, namun juga inspirasi bagi karyawan.

Pemimpin harus hadir untuk meyakinkan serta mengilhami pengikut untuk mencapai hasil yang luar biasa (Robbins, 2007). Peran seorang pemimpin diyakini akan membawa pengaruh terhadap sebuah perubahan sebuah organisasi. Perubahan organisasi merupakan usaha pihak manajemen untuk membuat pegawai dapat bertindak, berfikir, dan bekerja secara berbeda (Kreitner dan Kinicki, 2011).

Abouraira dan Othman (2017), menunjukkan bahwa kepemimpinan transformasional memiliki hubungan yang erat dengan kepuasan kerja, komitmen organisasi dan intensi keluar dalam sebuah organisasi. Pemimpin transformasional harus mendukung para pengikutnya untuk menumbuhkan persiapan yang lebih baik sehingga mampu meningkatkan kepuasan kerja dan komitmen organisasional yang akhirnya mengarah pada tingkat perputaran karyawan yang rendah.

Faktor lain yang mempengaruhi kinerja sumber daya manusia pada sebuah organisasi adalah adanya keterlibatan kerja. Keterlibatan kerja merupakan sebuah bukti bahwa karyawan sangat terlibat dalam pekerjaan yang sedang dijalani. Sehingga keterlibatan kerja dinilai begitu penting karena berkaitan dengan bagaimana karyawan mampu melakukan tugas serta tanggung jawabnya atau tidak (Kreitner dan Kinicki, 2011).

Beberapa penelitian terdahulu, misalnya Nazem dan Mozaiini (2014) menyatakan bahwa terdapat hubungan positif antara nilai kepemimpinan transformasional dengan keterlibatan kerja karyawan. Karena pemimpin transformasional memiliki kemampuan untuk menyatukan kepentingan organisasi dan anggotanya. Bukan hanya itu saja, namun juga mampu menginspirasi para pengikut serta memotivasi para karyawan sehingga mempengaruhi keterlibatan kerja dari pengikut atau sumber daya manusia dalam sebuah organisasi.

Beberapa penelitian sebelumnya juga menunjukkan bahwa peranan dari kepemimpinan transformasional terbukti mempengaruhi pengikutnya. Misalnya kepemimpinan transformasional ikut mempengaruhi performa dan sikap kerja karyawan sebuah perusahaan (Tsai et, al., 2009). Banyak organisasi atau perusahaan di dunia yang tentunya setuju akan pendapat ini. Hit and Ireland (2002) semakin menjelaskan bahwa esensi dari seorang pemimpin 
dapat dikatakan memiliki kepemimpinan yang baik jika ia mampu mengelola sumber daya dan kegiatan manajerial yang baik pula. Sehingga kunci utama dari semuanya ini adalah pada kinerja pemimpinnya.

Dalam melakukan tanggung jawabnya, seorang pengikut tidak terlepas dari dimensi budaya nasional yang menjadi orientasi individual. Hofstede (1980) menjelaskan bahwa budaya sebagai program mental kolektif dari masyarakat dalam sebuah lingkungan, yang dimiliki oleh satu masyarakat dan berebda dari kelompok masyarakat, suku, wilayah, kaum minoritas atau mayoritas, atau negara lainnya.

Adler dalam Beugeldisjk et. al (2016) menjelaskan bahwa budaya sebenarnya telah didefinisikan dalam ratusan cara. Tergantung pada perspektif teoritis yang dominan dan pendekatan metodologis yang diambil. Sementara itu Hofstede (2010) menjelaskan bahwa budaya merupakan sebuah pemrograman kolektif suatu pikiran yang membedakan antara kelompok satu dengan kelompok lainnya. Tentunya faktor budaya menjadi sebuah hal yang penting dalam mengelola sebuah organisasi dan bisnis. Beer dan Nohria (2000) mengungkapkan bahwa kesuksesan organisasi juga dapat tercapai apabila memiliki budaya organisasi yang baik sebagai salah satu sumber kesuksesannya. Dalam organisasi, pemimpin lebih mampu melibatkan seluruh anggotanya.

Perbedaan budaya dapat menyebabkan adanya perbedaan yang berkaitan erat dengan proses komunikasi, penggunaan bahasa, gaya bicara, komunikasi non verbal, penyelesaian konflik, dan perubahan organisasi (Treven et. al., 2008). Sehingga dengan menghargai adanya peranan budaya dalam organisasi, akan muncul pemahaman yang lebih baik terhadap manajemen serta perilaku organisasional.

Dimensi budaya pada akhirnya oleh Hofstede et. al. (2010) dibagi menjadi empat yaitu adanya rentang kekuasaan, kolektivisme yang berlawanan dengan individualisme, femininitas versus maskulinitas, dan penghindaran ketidakpastian. Rentang kekuasaan diartikan sebagai sejauhmana anggota organisasi atau institusi dengan kekuasaan yang lebih lemah di sebuah negara memiliki ekspektasi dan menerima kekuasaan yang terdistribusi secara tidak seimbang. Kedua adalah kolektivisme versus individualisme.

Kolektivisme diartikan sebagai sejauhmana individu melihat bahwa dirinya telah menjadi bagian dari orang atau kelompok lain. Biasanya orang dengan kolektivisme akan memperlakukan orang lain sama tanpa melihat hasil kinerja. Dan Hofstede mengakui bahwa Indonesia memiliki kolektivisme yang tinggi.

Maskulinitas menurut Hofstede (2010) mendefinisikan sebuah masyarakat dikatakan maskulin pada saat terlihat jelas perbedaan emosional antar gender. Misalnya pria tampak lebih tegas, tangguh, dan fokus kepada kesuksesan materiil. Sedangkan wanita lebih lembut. Sehingga peran emosional antar gender sangat perlu. Sementara itu, penghindaran ketidakpastian diartikan sebagai sejauhmana karyawan memiliki perasaan terancam oleh sebuah situasi yang bersifat belum pasti kejelasannya (Dorfman dan Howell, 1988).

Berdasarkan penelitian yang telah dilakukan Hofstede tahun 2001 pada perusahaan IBM, Indonesia berada dalam peringkat $8 / 9$ mengenai adanya budaya ketergantungan yang besar dari bawahan kepada pimpinan, peringkat 47/48 yang menegaskan bahwa Indonesia memiliki budaya kolektif. Kemudian Indonesia berada di posisi 30/31 untuk posisi maskulinitas, dan peringkat 41/42 untuk penghindaran ketidakpastian, sehingga Indonesia termasuk dalam kategori negara yang memiliki budaya tingkat penghindaran terhadap ketidakpastian yang tergolong kategori menengah kebawah. Peringkat tersebut merupakan hasil pemeringkatan dari 50 negara dari 3 wilayah. 
Dari pertimbangan inilah, penelitian mengenai pengaruh kepemimpinan transformasional terhadap keterlibatan kerja yang dimoderasi oleh rentang kekuasaan, kolektivisme, femininitas atau maskulinitas, dan penghindaran ketidakpastian penting untuk dilakukan..

\section{KAJIAN PUSTAKA DAN HIPOTESIS Kepemimpinan Transformasional}

Kepemimimpinan memiliki pengertian sebagai sebuah proses untuk mempengaruhi orang lain untuk mencapai tujuan yang ingin diperoleh (Kreitner dan Kinicki, 2011). Terdapat dua bentuk kepemimpinan, yaitu transaksional dan transformasional. Kepemimpinan transformasional merupakan salah satu konsep dari turunan konsep kepemimpinan selain kepemimpinan transaksional. Inilah yang menjadi konsep pertama yang akan dibahas oleh penulis. Konsep kedua adalah keterlibatan kerja sebagai teori yang dipengaruhi oleh kepemimpinan tranformasional. Konsep ketiga adalah penjelasan mengenai hubungan antara pengaruh kepemimpinan transformasional dengan keterlibatan kerja. Dan yang keempat adalah orientasi budaya individu berdasarkan budaya nasional Hofstede.

Kepemimpinan transformasional dinilai lebih dinilai mampu memberikan panutan pada pengikutnya. Mereka lebih visioner, dan mampu mengkomunikasikan tujuan organisasi yang akan dicapai dengan cara memotivasi dan membangung hubungan emosional yang kuat dengan karyawan (Sun dan Wang, 2016). Robbins (2006) menjelaskan bahwa pemimpin transformasional mampu memotivasi pengikutnya menuju ke sasaran yang ditetapkan dengan memperjelas persyaratan peran dan tugas. Namun pemimpinan transformasional terbentuk untuk melengkapi kepemimpinan transaksional.

Kepemimpinan transformasional terjadi ketika seorang pemimpin mampu mengubah pengikutnya dalam tiga hal penting (Thompson, 2008):

a. meningkatkan kesadaran bawahan tentang tugas mereka dan pentingnya melakukannya dengan baik,

b. membuat bawahan menyadari kebutuhan mereka akan pertumbuhan, perkembangan, dan pencapaian pribadi, dan

c. memotivasi bawahan untuk bekerja dengan baik demi kebaikan organisasi daripada secara ekslusif untuk keuntungan pribadi mereka.

Kepemimpinan transformasional sangat berpengaruh secara signifikan terhadap sikap dan perilaku para pengikutnya (Castro, et. al., 2008). Kepemimpinan transformasional juga diyakini cocok diterapkan dalam perusahaan yang menuntut pada pendekatan psikologis misalnya di bisnis perbankan (Abouraia dan Othman, 2017) dan bukan dalam bisnis yang memiliki banyak variasi, misalnya militer, rumah sakit, dan pendidikan (Bass, 1999). Kepemimpinan ini berbeda dengan transaksional yang lebih mengikat pengikutnya berdasarkan pemberian hukuman dan aturan sanksi tegas (Long, et. al., 2012).

\section{Keterlibatan Kerja}

Kanungo (1982), mengungkapkan bahwa keterlibatan kerja sangat berbeda dengan keterlibatan kerja secara umum. Keterlibatan kerja yang dimaksud adalah secara spesifik, yang menjelaskan bahwa karyawan bekerja karena adanya kebutuhan baik secara instrinsik dan ekstrinsik. Diefendorff et. al (2002), menjelaskan bahwa keterlibatan kerja menunjukkan tingkat integritas karyawan dengan pekerjaan yang dikerjakannya. Sehingga ketika karyawan memiliki integritas yang tinggi, maka ia akan melakukan pekerjannya dengan sebaik-baiknya. 
Singkatnya, keterlibatan kerja karyawan merupakan intensitas psikologis yang membentuk pekerjaannya (Lambert et. al., 2015).

Tiwari dan Singh (2014) menambahkan bahwa keterlibatan kerja merupakan sebuah keyakinan spesifik hubungan antara seseorang dengan pihak lain. Keterlibatan kerja diyakini memiliki dampak yang signifikan dengan hasil produktivitas karyawan dalam sebuah organisasi. Hal yang serupa juga dikemukakan oleh Abdallah et. al (2017) yang setuju bahwa keterlibatan kerja merupakan faktor pendukung utama sebuah keberhasilan organisasi. Sehingga dari beberapa pendapat tersebut menjelaskan bahwa keterlibatan kerja berkaitan erat dengan apa yang dirasakan oleh pegawai terhadap pekerjaannya yang nantinya juga berpengaruh pada pencapaian organisasi.

\section{Hubungan antara KepemimpinanTransformasional dengan Keterlibatan Kerja}

Bass (1999) menyatakan bahwa kepemimpinan transformasional dapat meningkatkan komitmen, keterlibatan, loyalitas, dan kinerja karyawan. Begitu juga dengan penelitian lainnya, di India Nazem dan Mozaiini (2014) membuktikan bahwa terdapat hubungan antara kepemimpinan transformasional dengan keterlibatan kerja karyawan. Sheikh et. al. (2013) dalam penelitiannya mengemukakan bahwa kepemimpinan transformasional mempengaruhi keterlibatan kerja secara positif.

Penelitian lainnya juga menyatakan adanya hubungan positif antara kepemimpinan transformasional dengan kinerja atau keterlibatan karyawan di industri pendidikan (Elgelal dan Noermijati, 2014). Javed dan Faroqhi (2013) juga membuktikan bahwa keterlibatan karyawan memiliki hubungan positif dengan kepempinan transformasional.

\section{Hipotesis 1 : Terdapat pengaruh positif kepemimpinan transformasional terhadap keterlibatan kerja karyawan \\ Orientasi Budaya Individu sebagai Variabel Pemoderasi}

Hofstede dalam Podrug et.al (2006) menunjukkan empat dimensi dari budaya nasional yang dapat membedakan antara budaya nasional dengan budaya nasional lainnya yang diidentifikasi sebagai dimensi rentang kekuasaan (dari besar ke kecil), kolektivisme versus individualisme, femininitas versus maskulinitas, dan penghindaran ketidakpastian (dari lemah ke kuat).

Hofstede (2010) mendefinisikan bahwa rentang kekuasaan diartikan sebagai sejauhmana anggota institusi dan organisasi dengan kekuasaan yang lebih lemah di sebuah wilayah dan menerima kekuasaan yang terdistribusi secara tidak seimbang. Dari pendapat tersebut menjelaskan pada bagaimana penerimaan anggota sebuah organisasi dengan kekuasaan yang lebih lemah terhadap distribusi kekuasaan yang kurang seimbang.

Maskulinitas menurut Hofstede (2010) mendefinisikan sebuah masyarakat dikatakan maskulin pada saat terlihat jelas perbedaan emosional antar gender. Misalnya pria tampak lebih tegas, tangguh, dan fokus kepada kesuksesan materiil. Dari pendapat ini juga menyatakan bahwa perbedaan gender ikut mempengaruhi tingkat emosional karyawan.

Sheikh et. al. (2013) dalam penelitiannya mengemukakan bahwa koletivisme ikut memoderasi pengaruh kepemimpinan transformasional terhadap keterlibatan kerja secara positif dan penghindaran ketidakpastian memoderasi secara negatif. Hasil penelitian tersebut yang mendasari penelitian ini. Beberapa penelitian lain, seperti Walumbwa et. al., (2007) juga menunjukan bahwa budaya kolektivitas memperkuat pengaruh kepemimpinan transformasional dan perilaku kerja karyawan. 
Berbagai penelitian tersebut kemudian dapat disusun menjadi beberapa hipotesis sebagai berikut:

Hipotesis 2 : Orientasi budaya individu tentang rentang kekuasaan karyawan akan memoderasi pengaruh antara kepemimpinan transformasional terhadap keterlibatan kerja karyawan. Pengaruh akan menjadi kuat ketika rentang kekuasaan rendah.

Hipotesis 3 : Orientasi budaya individu tentang kolektivisme karyawan akan memoderasi pengaruh kepemimpinan transformasional keterlibatan kerja karyawan. Pengaruh menjadi lebih kuat ketika tingkat kolektivisme tinggi.

Hipotesis 4 : Orientasi budaya individu tentang maskulinitas karyawan akan memoderasi pengaruh kepemimpinan transformasional keterlibatan kerja karyawan. Pengaruh menjadi lebih kuat ketika tingkat maskulinitas tinggi.

Hipotesis 5 : Orientasi budaya individu tentang penghindaran ketidakpastian karyawan akan memoderasi pengaruh kepempimpinan transformasional terhadap keterlibatan kerja karyawan. Pengaruh menjadi lebih kuat ketika tingkat penghindaran ketidakpastian rendah

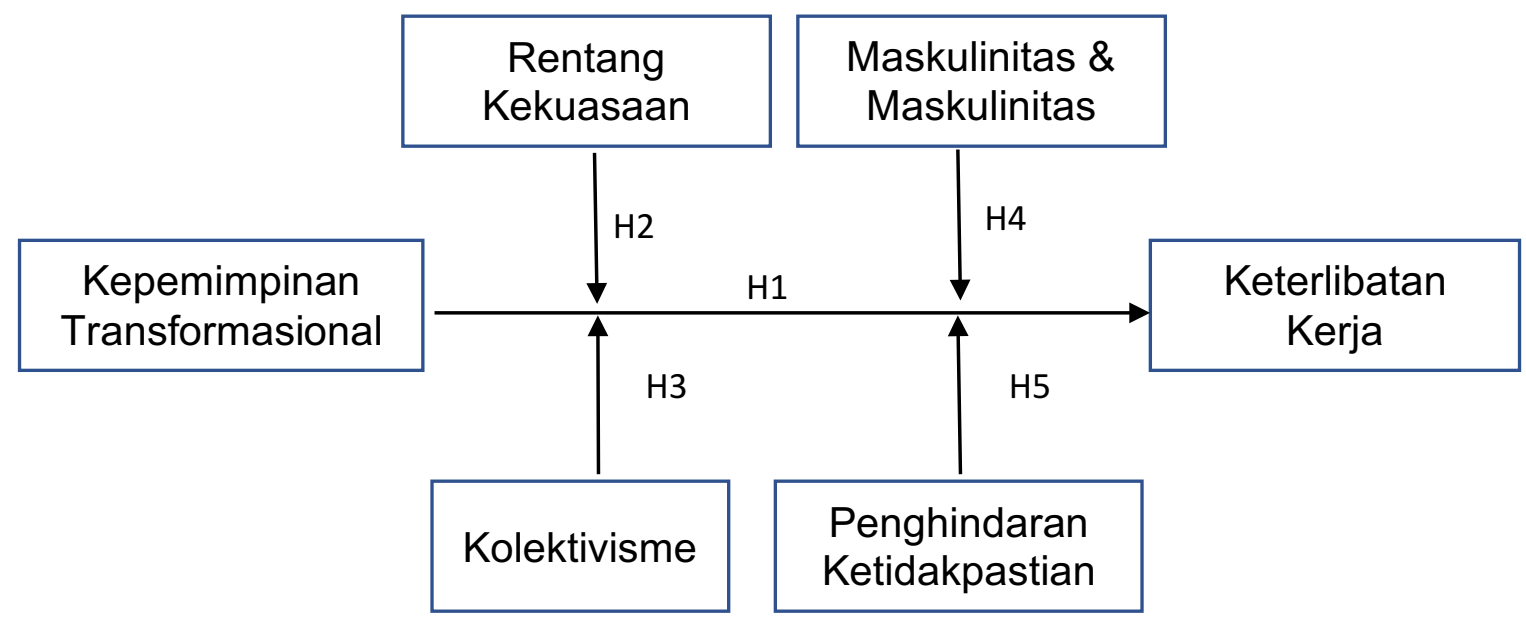

Gambar 1. Model Penelitian

\section{METODE PENELITIAN}

Penelitian ini termasuk dalam kategori penelitian crossectional, yaitu penelitian yang hanya mengambil data melalui penyebaran kuesioner hanya dalam satu saat saja dengan menggunakan desain survei sebagai teknik pengumpulan data yang bertujuan untuk memperoleh keterangan secara nyata melalui penggunaan kuesioner sebagai alat pengumpul data yang utama (Sekaran, 2006). Responden diminta untuk memberikan penilaian atas setiap pertanyaan dengan skala likert yang menggunakan skala ordinal 1 untuk sangat tidak setuju, 2 untuk tidak setuju, 3 untuk netral, 4 untuk setuju dan sangat setuju dengan skala ordinal 5.

Populasi yang menjadi subyek dalam penelitian ini adalah karyawan manajemen baik dari lini bawah sampai atas kantor pusat perusahaan perbankan nasional di Jakarta berjumlah 120 karyawan. Jumlah sampel tersebut berdasarkan lima kali estimated parameter (Hair et. al., 1998). Sehingga jumlah sampe minimal adalah 100 orang. Dalam penelitian ini, teknik 
pengambilan sampel yang digunaka adalah non probability samplin tipe purposive sampling yang memiliki arti pengambilan sampel yang tidak memberikan peluang atau kesempatan sama bagi setiap variabel atau anggota populasi untuk dipilih menjadi sampel (Sekaran, 2006).

\section{Desain penelitian}

Penelitian ini merupakan studi formal yang ditandai dengan melibatkan prosedur yang tepat dan spesifikasi sumber data. Sementara itu dimensi waktu penelitian ini adalah crosssectional studies, sehingga penelitian ini dilakukan di satu waktu saja dan mempresentasekan sebuah keadaan pada satu waktu saja (Cooper dan Sandler, 2014). Metode pengambilan data dilakukan dengan cara mengadakan survei terhadap tim manajemen baik dari lini bawah sampai atas pada kantor pusat salah satu perusahaan perbankan nasional di Jakarta dengan total karyawan sejumlah 120 orang. Penelitian ini merupakan lanjutan penelitian sebelumnya yang pernah diteliti mengenai evaluasi implementasi penerapan strategi kredit macet pada tahun 2015, yang salah satunya disebabkan oleh faktor kepemimpinan. Untuk teknik pengambilan sampel dilakukan dengan cara acak. Dan alat pengambilan keputusan dengan menggunakan kuesioner.

\section{Instrumen penelitian}

Dalam melakukan penelitian dan sebagai alat ukut kepemimpinan transformasional dalam penelitian ini diadaptasi dari Multifactor Leadership Questionairre oleh Bernard M. Bass dan Bruce J. Avolio dengan dua puluh komponen pertanyaan.

Tabel 1. Komponen pertanyaan variabel kepemimpinan transformasional

\begin{tabular}{|l|l|l|}
\hline No & \multicolumn{1}{|c|}{ Komponen Pertanyaan } & Jumlah pertanyaan \\
\hline 1 & $\begin{array}{l}\text { Gaya kepemimpinan yang menitikberatkan pada } \\
\text { rangsangan intelektual atau melalui pendekatan } \\
\text { rasional }\end{array}$ & 1 sampai dengan 4 \\
\hline 2 & $\begin{array}{l}\text { Gaya kepemimpinan yang idealistis dan dipengaruhi } \\
\text { oleh perilaku pemimpin }\end{array}$ & 5 sampai dengan 8 \\
\hline 3 & $\begin{array}{l}\text { Gaya kepemimpinan yang mengutamakan motivasi } \\
\text { kerja yang inspirational atau penuh dengan inspirasi }\end{array}$ & 9 sampai dengan 12 \\
\hline 4 & $\begin{array}{l}\text { Gaya kepemimpinan pengaruh idealis } \\
\text { Gaya kepemimpinan dengan mempertimbangkan } \\
\text { mengenai kepentingan individu }\end{array}$ & 13 sampai dengan 16 \\
\hline 5
\end{tabular}

Untuk keterlibatan kerja dalam penelitian ini diukur dengan menggunakan skala dari Kanungo (1982) dengan sepuluh item dengan contoh pada tabel berikut:

Tabel 2. Komponen pertanyaan keterlibatan kerja

\begin{tabular}{|ll|}
\hline & \multicolumn{1}{|c|}{ Kuesinoner Keterlibatan Kerja (Job Involvement) } \\
\hline 1. & The most important things that happen to me involve my present job \\
\hline 2. & To me, my job is only a small part of who I am \\
\hline 3. & I am very much involved personally in my job \\
\hline 4. & I live, eat and breathe my job \\
\hline
\end{tabular}




\begin{tabular}{|ll|}
\hline \multicolumn{1}{|c|}{ Kuesinoner Keterlibatan Kerja (Job Involvement) } \\
\hline $5 . \quad$ Most of my interests are centered around my job \\
\hline $\begin{array}{l}\text { 6. } \\
\text { break }\end{array}$ \\
\hline $7 . \quad$ Usually I feel detached from my job \\
\hline 8. & Most of my personal life goals are job-oriented \\
\hline 9. & I consider my job to be very central to my existence \\
\hline 10. & I like to be absorbed in my job most of the time \\
\hline
\end{tabular}

Sementara itu untuk contoh kuesioner orientasi nilai budaya individual memiliki masing-masing lima (5) dan enam (6) pertanyaan yang masing-masing pertanyaan akan diukur menggunakan skala nilai budaya atau kultural dari Donthu dan Yoo (Yoo et. al., 2011). Kecuali pada dimensi maskulinitas atau maskulinitas. Pada skala tersebut diambil contoh pada beberapa acuan mengenai pernyataan yang mendukung mengenai orientasi tersebut. Dan kuesioner tersebut dapat dicontohkan pada tabel dibawah:

Tabel 3. Komponen pertanyaan dimensi kolektivitas

\begin{tabular}{|ll|}
\hline \multicolumn{1}{|c|}{ Kuesioner Dimensi Kolektivitas (Collectivism) } \\
\hline 1. & Individuals should sacrifice self-interest for the group \\
\hline 2. & Individuals should stick with the group even through difficulties \\
\hline 3. & Group welfare is more important than individual reward \\
\hline 4. & Group success is more important than individual success \\
\hline $\begin{array}{l}\text { 5. } \\
\text { group }\end{array}$ \\
\hline 6. & Group loyalty should be encouraged even if individual goals suffer \\
\hline
\end{tabular}

Tabel 4. Komponen pertanyaan dimensi rentang kekuasaan

\section{Kuesioner Dimensi Rentang Kekuasaan (Power Distance)}

1. People in higher positions should make most decisions without consulting people in lower positions

2. People in higher positions should not ask the opinions of people in lower positions too frequently

3. People in higher positions should avoid social interaction with people in lower positions

4. People in lower positions should not disagree with decisions by people in higher positions

5. People in higher positions should not delegate inportat tasks to people in lower positions 
Tabel 5. Komponen pertanyaan dimensi maskulinitas

\section{Kuesioner Dimensi Maskulinitas (Masculinity Avoidance)}

1. Work or decide something with feelings

2. Make emotional approach to fellow employees

3. Male employees are able to do jobs faster than female employees

4. Physical power affects performance

5. Work will be done quickly when done together

Tabel 6. Komponen pertanyaan dimensi penghindaran ketidakpastian

Kuesioner Dimensi Penghindaran Ketidakpastian (Uncertainty Avoidance)

1. It is important to have instructions spelled out in detail so that I always know what I'm expected to do

2. It is important to closely follow instructions and procedures

3. Rules and regulations are important because they inform me of what is expected of me

4. Standardized work procedures are helpful

5. Instructions for operations are important

\section{Uji Validitas dan Reabilitas}

Uji validitas pada penelitian ini dilakukan menggunakan analisis faktor. Karena uji validitas ini menunjukkan seberapa baik hasil-hasil yang diperoleh dari penggunaan suatu pengukur sesuai dengan teori yang digunakan untuk mendefinisikan suatu konstruk (Mustakini, 2008). Tingkat validitas instrumen dilihat pada tinggi rendahnya skor muatan pada masingmasing item penelitian pada konstruk yang dimaksud oleh item-item tersebut (Mustakini, 2008). Dalam menguji validitas konstruk menggunakan analisis faktor, dengan estimasi standardized loading harus sebesar 0,5 atau lebih, dan idealnya adalah 0,7 atau lebih (Hair et. al., 2010).

Reliabilitas dalam penelitian ini diukur dengan menggunakan Cronbach's coefficient alpha. Dalam pengukuran tersebut sebuah instrumen dinyatakan baik apabila koefisien reliabilitas dekat dengan 1,0. Reliabilitas intrumen dianggap lemah saat alpha kurang dari 0,60 dan dapat diterima saat alpha berada pada kisaran 0,70 serta dianggap baik saat alpha berada diatas 0,80 (Sekaran dan Bougie, 2013).

\section{Teknik Analisis Data}

Dalam penelitian ini menggunakan metode analisis regresi berjenjang untuk menguji efek utama dan efek moderasi. Tujuan digunakannya metode ini adalah agar dapat melihat pengaruh dari variabel pemoderasi terhadap pengaruh variabel bebas atau independen terhadap variabel terikat atau dependen. Dalam menganalisa efek moderasi, maka akan dilakukan meancentered pada data untuk menghindari multicolinierity saat dilakukan perkalian pada variabel moderasi ( $\mathrm{Wu}, 2008)$.

Untuk melakukan metode analisis regresi berjenjang, dibutuhkan dua persamaan regresi yang terdiri dari persamaan pertama yang berisikan dampak atau efek utama dan persamaan 
kedua yang berisi efek utama serta efek moderasi (Mustakini, 2008). Baron dan Kenny (1986) juga menjelaskan bahwa syarat didukungnya hipotesis moderasi adalah apabila hipotesis moderasi mendukung interaksi variabel bebas dengan variabel pemoderasi yang bernilai signifikan. Analisis data membagi pengaruh variabel pemoderasi pada kategorisasi rendah (ratarata -1 deviasi standar) dan tinggi (rata-rata +1 deviasi standar). Selanjutnya disajikan grafik yang menggambarkan efek variabel pemoderasi dalam kategorisasi rendah dan tinggi pada pengaruh kepemimpinan transformasional terhadap keterlibatan kerja.

\section{HASIL DAN PEMBAHASAN}

Responden pada penelitian ini adalah karyawan manajemen baik dari lini bawah sampai atas kantor pusat perusahaan perbankan nasional di Jakarta berjumlah 120 karyawan. Total kuesioner berjumlah 120 yang juga disesuaikan berdasarkan jumlah karyawan perusahaan tersebut. Dari total kuesioner yang dibagi, total kuesioner yang kembali berjumlah 115 kuesioner. Dari total tersebut 110 kuesioner dapat dianalisis lebih lanjut, sedangkan 5 kuesioner dianggap gagal karena tidak lengkap dalam mengisi data.

Adapun karakteristik responden adalah sebagai berikut:

Tabel 7. Deskripsi Responden

\begin{tabular}{|c|c|c|}
\hline Karakteristik & Kategori & Frekuensi \\
\hline \multirow[t]{2}{*}{ Jenis Kelamin } & Laki-Laki & 68 orang \\
\hline & Perempuan & 42 orang \\
\hline \multirow[t]{4}{*}{ Usia } & $20-29$ tahun & 51 orang \\
\hline & $30-39$ tahun & 37 orang \\
\hline & $40-49$ tahun & 17 orang \\
\hline & $>50$ tahun & 5 orang \\
\hline \multirow[t]{2}{*}{ Pendidikan } & $\mathrm{S} 1$ & 78 orang \\
\hline & Diploma & 32 orang \\
\hline \multirow[t]{2}{*}{ Jabatan } & $\begin{array}{l}\text { Staff divisi } \\
\text { penyiaran } \mathrm{TV}\end{array}$ & 60 orang \\
\hline & $\begin{array}{l}\text { Staff divisi } \\
\text { penyiaran radio }\end{array}$ & 50 orang \\
\hline \multirow[t]{4}{*}{ Masa Kerja } & $<1$ tahun & 13 orang \\
\hline & $1-2$ tahun & 29 orang \\
\hline & $3-4$ tahun & 58 orang \\
\hline & $>5$ tahun & 10 orang \\
\hline
\end{tabular}

Sumber: Hasil olah data (2017)

\section{Uji Hipotesis}

\begin{tabular}{llcccccc}
\hline Model & $\begin{array}{c}\text { Variabel } \\
\text { Independen }\end{array}$ & $\mathbf{B}$ & $\boldsymbol{\beta}$ & $\mathbf{F}$ & $\mathbf{R}$ & $\mathbf{R 2}$ & Sig \\
\hline 1 & $\begin{array}{l}\text { Kepemimpinan } \\
\text { Transformasional }\end{array}$ & 1,675 & 0,350 & 13,975 & 0,310 & 0,140 & 0,00 \\
& & & & & & &
\end{tabular}


Berdasarkan tabel diatas menunjukkan besarnya nilai korelasi sebesar 0,310 dan koefisien determinasi sebesar 0,140. Artinya bahwa pengaruh variabel kepemimpinan transformasional terhadap variabel job involvement adalah sebesar $14 \%$, sedangkan sisanya dipengaruhi oleh variabel lain. Nilai F hitung sebesar 13,975 dan terbukti lebih besar dibandingkan dengan $\mathrm{F}$ tabel $(\mathrm{df}=1, \mathrm{n}=110)$ sebesar 2,32. Sehingga variabel kepemimpinan transformasional dapat digunakan untuk memprediksi variabel job involvement.

Sedangkan untuk nilai B pada konstan menunjukkan angka 1,675 dan nilai $\beta$ pada transformasional leadership sebesar 0,350 sehingga dapat dituliskan persamaan regresinya $\mathrm{Y}=$ $1,675+0,350 X$. Sehingga dari persamaan tersebut dapat diterjemahkan koefisien regresi X sebesar 0,350 menyatakan bahwa setiap penambahan 1 nilai kepemimpinan transformasional, maka nilai job involvement bertambah sebesar 0,365. Dari hasil diatas maka diketahui signifikan $0,00<0,05$ yang berarti kepemimpinan transformasional berpengaruh signifikan terhadap keterlibatan kerja bawahan secara positif. Berdasarkan hasil uji statistik tersebut terbukti bahwa hipotesis pertama dari penelitian ini terdukung.

Hipotesis kedua menguji pengaruh kepemimpinan terhadap keterlibatan kerja dengan rentang kekuasaan sebagai variabel pemoderasi. Dan hasil pengujian regresinya adalah sebagai berikut:

Tabel 9. Uji Hipotesis Kedua

\begin{tabular}{ccccccc}
\hline \multirow{2}{*}{ Variabel } & \multicolumn{3}{c}{ Persamaan 1 } & \multicolumn{3}{c}{ Persamaan 2 } \\
& R2 & B & $\boldsymbol{P}$ & R2 & $\boldsymbol{\beta}$ & $\boldsymbol{P}$ \\
\hline X & \multirow{2}{*}{0,161} & 0,310 & 0,001 & & 0,325 & 0,001 \\
MV1 & & 0,110 & 0,041 & 0,165 & 0,097 & 0,090 \\
MO1 & & & & & 0,070 & 0,052 \\
\hline
\end{tabular}

Pada persamaan 1, ditunjukkan tentang besarnya nilai koefisien determinasi sebesar 0,161 yang artinya bahwa pengaruh variabel kepemimpinan transformasional dan rentang kekuasaan terhadap variabel keterlibatan kerja sebesar 16,1\%. Sedangkan pada model 2, ditunjukkan tentang besarnya nilai koefisien determinasi sebesar 0,165 yang mengandung pengertian bahwa pengaruh variabel kepemimpinan transformasional terhadap variabel keterlibatan kerja saat dimoderasi oleh variabel rentang kekuasaan adalah sebesar 16,5\%. Dari kedua hasil tersebut terdapat kenaikan nilai namun tidak signifikan secara statistik. Dinilai tidak signifikan karena nilainya tidak secara signifikan (nilai $\mathrm{p}=0,052>0,05$ ). Sehingga berdasarkan hasil uji statistik pada penelitian ini terbukti bahwa rentang kekuasaan tidak memoderasi antara kepemimpinan transformasional dengan keterlibatan kerja bawahan karena tidak mendapatkan dukungan yang sangat signifikan pada uji statistik, sehingga hipotesis 2 ditolak.

Untuk hipotesis ketiga menguji pengaruh kepemimpinan transformasional terhadap keterlibatan kerja dengan kolektivisme sebagai variabel pemoderasi. Adapun hasil pengujian regresinya adalah sebagai berikut:

Tabel 10. Uji Hipotesis Ketiga

\begin{tabular}{lccrcrc}
\hline \multirow{2}{*}{ Variabel } & \multicolumn{3}{c}{ Persamaan 1 } & \multicolumn{3}{c}{ Persamaan 2 } \\
& $\mathbf{R 2}$ & $\boldsymbol{\beta}$ & $\boldsymbol{P}$ & $\mathbf{R 2}$ & $\boldsymbol{\beta}$ & $\boldsymbol{P}$ \\
\hline X & 0,230 & 0,230 & 0,055 & 0,250 & 0,296 & 0,008 \\
MV2 & & 0,271 & 0,005 & & 0,242 & 0,006 \\
MO2 & & & & & 0,225 & 0,054 \\
\hline
\end{tabular}


Pada model 1, ditunjukkan besarnya koefisien determinasi $\left(\mathrm{R}^{2}\right)$ sebesar 0,230 yang mengandung pengertian bahwa pengaruh variabel kepemimpinan transformasional dan kolektivisme terhadap variabel keterlibatan kerja adalah sebesar 23\%. Pada model 2, ditunjukkan besarnya koefisien determinasi $\left(\mathrm{R}^{2}\right)$ sebesar 0,250 yang mengandung pengertian bahwa pengaruh variabel kepemimpinan transformasional dan kolektivisme terhadap variabel keterlibatan kerja adalah sebesar 25\%. Berdasarkan hasil perhitungan kedua model tersebut terdapat peningkatan namun tidak signifikan secara statistik. Dinilai tidak signifikan karena nilainya tidak secara signifikan (nilai $\mathrm{p}=0,054>0,05$ ). Sehingga berdasarkan hasil uji statistik pada penelitian ini terbukti bahwa kolektivisme tidak memoderasi pengaruh kepemimpinan transformasional terhadap keterlibatan kerja bawahan karena tidak mendapatkan dukungan signifikan pada uji statistik, sehingga hipotesis 3 ditolak.

Untuk hipotesis keempat menguji pengaruh kepemimpinan transformasiona terhadap keterlibatan kerja dengan maskulinitas sebagai variabel pemoderasi. Adapun hasil pengujian regresi adalah sebagai berikut:

Tabel 11. Uji Hipotesis Keempat

\begin{tabular}{lcccrrr}
\hline \multirow{2}{*}{ Variabel } & \multicolumn{3}{c}{ Persamaan 1 } & \multicolumn{3}{c}{ Persamaan 2 } \\
& R2 & $\boldsymbol{\beta}$ & $\boldsymbol{P}$ & R2 & $\boldsymbol{\beta}$ & $\boldsymbol{P}$ \\
\hline $\mathrm{X}$ & 0,220 & 0,242 & 0,045 & 0,241 & 0,286 & 0,009 \\
MV2 & & 0,275 & 0,005 & & 0,230 & 0,006 \\
MO2 & & & & & 0,215 & 0,058 \\
\hline
\end{tabular}

Dari hasil diatas pada model 1, ditunjukkan besarnya koefisien determinasi sebesar 0,220 yang mengandung pengertian bahwa pengaruh variabel kepemimpinan transformasional dan maskulinitas terhadap variabel keterlibatan kerja adalah sebesar 22\%. Pada model 2, ditunjukkan besarnya nilai koefisien determinasi sebesar 0,241 yang mengandung pengertian bahwa pengaruh variabel kepemimpinan transformasional terhadap varibel keterlibatan kerja saat dimoderasi oleh variabel maskulinitas adalah sebesar 24,1\%. Sehingga ada peningkatan dari kedua persamaan tersebut. Namun peningkatan tersebut tidak terlalu signifikan. Adapun nilai koefisien interaksi adalah $\mathrm{p}=0,058>0,05$. Dan berdasarkan hasil uji statistik pada penelitian ini terbukti bahwa maskulinitas tidak memoderasi pengaruh kepemimpinan transformasional terhadap keterlibatan kerja bawahan karena tidak mendapatkan dukungan signifikan pada uji statistik, dan hipotesis ke 4 ditolak.

Dan untuk hasil hipotesis kelima adalah menguji pengaruh kepemimpinan transformasional terhadap keterlibatan kerja dengan penghindaran ketidakpastian sebagai variabel pemoderasi. Hasil pengujian regresi adalah sebagai berikut:

Tabel 12. Uji Hipotesis Kelima

\begin{tabular}{lcccccc}
\hline \multirow{2}{*}{ Variabel } & \multicolumn{3}{c}{ Persamaan 1 } & \multicolumn{3}{c}{ Persamaan 2 } \\
& R2 & $\boldsymbol{\beta}$ & $\boldsymbol{P}$ & $\mathbf{R 2}$ & $\mathbf{B}$ & $\boldsymbol{P}$ \\
\hline $\mathrm{X}$ & 0,150 & 0,374 & 0,001 & 0,175 & 0,459 & 0,001 \\
MV3 & & 0,010 & 0,890 & & 0,050 & 0,585 \\
MO3 & & & & & 0,224 & 0,025 \\
\hline
\end{tabular}

Dari data diatas ditunjukkan bahwa model 1 menjelaskan bahwa besarnya nilai koefisien 
determinasi sebesar 0,150 yang mengandung pengertian bahwa pengaruh variabel kepemimpinan transformasional dan penghindaran ketidakpastian terhadap variabel keterlibatan kerja adalah sebesar 15\%. Sedangkan pada model 2, ditunjukkan bahwa besarnya nilai koefisien korelasi determinasi sebesar 0,175 yang mengandung pengertian bahwa pengaruh variabel kepemimpinan transformasional dan penghindaran ketidakpastian terhadap variabel keterlibatan kerja adalah sebesar 17,5\%. Dan terlihat pula adanya kenaikan hasil koefisien determinasi. Namun tidak signifikan secara statistik.

Pada uji signifikansi, koefisien regresi tersebut signifikan secara statistik pada $\alpha=5 \%$ (nilai $\mathrm{p}=0,025<0,5$ ) sehingga terbukti bahwa variabel penghindaran ketidakpastian memoderasi pengaruh kepemimpinan transformasional terhadap keterlibatan kerja. Namun, pengaruh tersebut bernilai positif $(\beta=0,024)$ sehingga hipotesis 5 ditolak.

\begin{tabular}{|c|c|c|c|}
\hline No. & Hipotesis & Hasil & Keterangan \\
\hline 1 & $\begin{array}{l}\text { Terdapat pengaruh positif kepemimpinan } \\
\text { transformasional terhadap keterlibatan } \\
\text { kerja }\end{array}$ & Diterima & $\begin{array}{c}\mathrm{p}=0,00<0,05 \\
\beta=0,350\end{array}$ \\
\hline 2 & $\begin{array}{l}\text { Rentang kekuasaan } \begin{array}{r}\text { memoderasi } \\
\text { pengaruh } \\
\text { transformasional terhadap kemimpinan }\end{array} \\
\text { kerja dengan bentuk negatif }\end{array}$ & Ditolak & $\mathrm{p}=0,052$ \\
\hline 3 & $\begin{array}{l}\text { Kolektivisme memoderasi pengaruh } \\
\text { kepemimpinan transformasional terhadap } \\
\text { keterlibatan kerja dengan bentuk positif. }\end{array}$ & Ditolak & $\mathrm{p}=0,054$ \\
\hline 4 & $\begin{array}{l}\text { Maskulinitas memoderasi pengaruh } \\
\text { kepemimpinan transformasional terhadap } \\
\text { keterlibatan kerja dengan bentuk positif }\end{array}$ & Ditolak & $p=0,058$ \\
\hline 5 & $\begin{array}{l}\text { Penghindaran ketidakpastian memoderasi } \\
\text { kepemimpinan transformasional terhadap } \\
\text { keterlibatan kerja sacara negatif. }\end{array}$ & Ditolak & $\begin{array}{l}p=0,025 \\
\beta=0,224\end{array}$ \\
\hline
\end{tabular}

\section{Pembahasan}

Pada uji hipotesis yang pertama, membuktikan bahwa kepemimpinan transformasional ikut mempengaruhi secara positif adanya keterlibatan kerja. Sehingga semakin tinggi kepemimpinan transformasional, maka semakin meningkat keterlibatan kerja dari karyawan. Sheikh et. al (2013) juga menekankan hal yang serupa, bahwa keterlibatan kerja karyawan pada level yang tinggi. Hasil serupa juga didukung oleh beberapa penelitian sebelumnya seperti Nazem dan Mozaini (2014). Semakin empiris semakin tinggi pula tingkat kepemimpinan transformasional di perusahaan broascasting tersebut.

Hasil penelitian menunjukkan bahwa kepemimpinan transformasional pada kantor pusat perusahaan perbankan memiliki pengaruh yang kuat akan keterlibatan karyawan. Pengaruh yang kuat tersebut diperoleh melalui kepedulian secara personal bukan hanya tim dan motivasi yang dinilai inspirasional dari pemimpin. Pada penelitian di kantor pusat perusahaan perbankan ini ditemukan nilai kepemimpinan transformasional yang tinggi dan keterlibatan kerja yang sedang. Namun meskipun demikian, apabila melihat hasil penelitian tersebut, sangat mungkin bahwa keterlibatan kerja karyawan akan semakin meningkat seiring dengan menerapkan nilainilai yang terkandung dalam kepemimpinan transformasional. 
Pada analisis data untuk hipotesis kedua, hasil empiris tidak terdukung dengan baik. Sehingga kepemimpinan transformasional tidak terbukti secara signifikan terhadap keterlibatan kerja dengan rentang kekuasaan sebagai variabel pemoderasi. Penelitian sebelumnya, Sheikh et. al., (2013) menyatakan bahwa rentang kekuasaan tidak memoderasi pengaruh kepemimpinan transformasional dan keterlibatan kerja dikarenakan rendahnya tingkat rentang kekuasaan. Subiyantoro dan Hatane (2007) menjelaskan mengenai menipisnya rentang kekuasaan di masyarakat. Dan pernyataan tersebut sesuai dengan apa yang terjadi pada kantor pusar perusahaan perbankan tersebut. Tentunya hal ini sangat berbanding terbalik dengan pernyataan yang dikeluarkan oleh pendapat Hofstede (2010), yang menjelaskan bahwa Indonesia memiki tingkat rentang kekuasaan yang cukup tinggi.

Pada uji hipotesis ketiga kolektivisme terbukti tidak memoderasi pengaruh pada kepemimpinan transformasional terhadap keterlibatan kerja. Hasil ini tentu berbeda dengan penelitian sebelumnya, misalnya Sheikh et. al, (2013) bahwa kolektivisme memoderasi pengaruh kepemimpinan transformasional dengan keterlibatan kerja. Sebenarnya terdapat kenaikan tingkat kolektivisme dalam penelitian ini, namun tidak terlalu tinggi bahkan tergolong rendah. Cheng et. al., (2012) menjelaskan bahwa ada variabel lain yang ikut mempengaruhi antara kepemimpinan transformasional terhadap keterlibatan karyawan. Yaitu variabel penularan emosional. Namun belum bisa dipastikan apakah variabel penularan emosional merupakan penyebab rendahnya hasil hipotesis ketiga ini.

Hasil yang sama juga diperoleh pada hipotesis keempat yang terbukti bahwa karyawan perusahaan broadcast lebih cenderung menggunakan maskulinitas dibandingkan maskulinitas. Hasil lainnya adalah terbukti bahwa maskulinitas tidak terlalu mempengaruhi hubungan kepemimpinan transformasional terhadap keterlibatan kerja karyawan. Sedangkan untuk hipotesis kelima ditegaskan bahwa penghindaran ketidakpastian memoderasi pengaruh kepemimpinan transformasional dengan keterlibatan kerja. Bentuk pengaruh tersebut berbentuk positif. Semakin tinggi penghindaran ketidakpastian, semakin kuat pengaruh kepemimpinan transformasional terhadap keterlibatan kerja. Ini tentunya sangat berbeda dengan penelitian Sheikh et. al., (2013) yang menegaskan bahwa penghindaran ketidakpastian memiliki dampak negatif dalam memoderasi pengaruh kepemimpinan transformasional terhadap keterlibatan kerja.

Untuk penyebab penghindaran ketidakpastian yang terjadi di kantor pusat perusahaan perbankan selain dari faktor kepemimpinan kemungkinan dari adanya jumlah pesaing yang terus meningkatkan program penyiarannya setiap tahunnya. Nilai rata-rata penghindaran ketidakpastian pada perusahaan ini berada dalam kategori yang tinggi. Hal ini sangat berbeda dengan pendapat Hofstede (2010) yang menyatakan bahwa tingkat penghindaran ketidakpastian Indonesia tergolong menengah ke rendah. Kreitner dan Kenicki (2011) menyatakan bahwa penghindaran ketidakpastian yang tinggi membuat kecenderungan tidak dapat menggung resiko.

\section{PENUTUP}

Penelitian ini menghasilkan temuan bahwa kepemimpinan transformasional berpengaruh positif terhadap keterlibatan kerja karyawan. Sehingga semakin tinggi tingkat kepemimpinan transformasional, maka akan semakin tinggi pula tingkat keterlibatan karyawan dalam sebuah organisasi. Sementara itu beberapa temuan yang berpengaruh negatif akan hubungan kepemimpinan transformasional terhadap keterlibatan kerja karyawan adalah adalah 
orientasi budaya individual yang didalamnya termasuk rentang kekuasaan, kolektivisme, maskulinitas, dan penghidaran ketidakpastian. Penyebab kurangnya keterlibatan karyawan bisa jadi dipengaruhi faktor eksternal yang dapat menjadi variabel lain sebagai pemoderasi nya.

\section{REFERENSI}

Abdallah A.B., Obeidat B.Y., Aqqad N.O., Janini M.N.K.A., and Dahiyat S.E., 2017. An Integrated Model of Job Involvement, Job Satisfaction and Organizational Commitment: A Structural Analysis in Jordan's Banking Sector. Scientific Research Publishing. Vol. 9 p. 28-53

Abouraia, M.K. and Othman, S.M., 2017. Transformational Leadership, Job Satisfaction, Organizational Commitment, and Turnover Intentions: The Direct Effects among Bank Representatives. American Journal of Industrial and Business Management, 7, p. 404423

Baron, R. M., \& Kenny. D.A., 1986. The Moderator-Mediator Variable Distinction in Social Psychological Research: Conceptual, Strategic, and Statistical Considerations. Journal of Personality and Social Psychology, 51, 6, 1173-1182.

Bass, B.M., 1999. Two Decades of Research and Development in Transformational Leadership. European Journal of Work and Organizational Psychology, 8, 1, 9-32.

Beer. M., and Nohria, N., 2014. Cracking the Code of Change. Harvard Business Review.

Bougelsdijk, S., Kostova, T., and Roth K., 2016. An Overview of Hofstede-inspired countrylevel culture research in international business since 2006. Journal of International Business Studies.

Castro, C.B., Periñan, M.M.V., and Bueno, J.C.C. 2008. Transformational Leadership and Followers' Attitudes: The Mediating Role of Psychological Empowerment, The International Journal of Human Resource Management, 19, 10, 1842-1863.

Cooper, D.R. \& Schindler, P.S., 2014. Business Research Methods, $12^{\text {th }} e d$. New York: McGraw-Hill.

Dieffendorf, M.J., Brown, J. D., Kamin, M.A., and Lord, G. R. 2002. Examining The roles of Job involvement and Work Centrality in predicting organizational citizenship behaviours and job performance. Journal of Organizational Behavior, 23, 93-108.

Dorfman, P.W., and Howell, J.P. 1988. Dimensions of National Culture and Effective Leadership Patterns: Hofstede Revisited, Advances in International Comparative Management, 3, 127-150.

Elgelal, K. S. K., and Noermijati. 2014. The Influences of Transformational Leadership on Employees Performance (A Study of the Economics and Business Faculty Employee at University of Muhammadiyah Malang). Asia-Pasific Management and Business Application, 3 (1) p. 48-66

Hair, J.F., Black, W.C., Babin, B.J., \& Anderson, R.E. 2010. Multivariate Data Analysis: A Global Perspective. $7^{\text {th }}$ ed. Upper Saddle River: Prentice Hall.

Hofstede, G. 1980. Motivation, Leadership, and Organization: Do American Theories Apply Abroad?. Organizational Dynamics, 9, 1, 42-63.

Hofstede, G., and Minkov, M. 2010. Cultures and Organization, Software of The Mind, Intercultural Cooperation and Its Importance for Survival, $3^{\text {rd }} e d$. New York: McGrawHill.

Javeed, T. and Farooqi, Y.A. 2013. Impact of Transformational Leadership Style on Employees' 
Satisfaction and Well-Being with Working Conditions as Mediator, International Journal of Multidisciplinary Sciences and Engineering, 4, 7, p.1-8.

Kanungo, R.N. 1982. 'Measurement of Job and Work Involvement,' Journal of Applied Psychology, 67, 3, p.341-349.

Kreitner, R., and Kinicki, A. 2011. Organizational Behavior. $9^{\text {th }} e d$. New York: McGraw-Hill. Lambert, E. G., Qureshi, H., Hogan, N.L., Klahm C., Smith B., and Frank J. 2015. The Associaton of Job Variables With Job Involvement, Job Satisfaction, and Organizational Commitement Among Indian Police Officers. International Criminal Justice Review, Vol. 25 (2) p.194-213

Long C.S., Thean L.Y., Ismail W.K.W., and Jusoh A. 2012. Leadership Styles and Employees' Turnover Intention: Exploratory Study of Academic Staff in a Malaysian College. World Applied Sciences Journal, 19 (4) p. 575-581

Mustakini, J.H. 2008. Metodologi Penelitian Sistem Informasi: Pedoman dan Contoh Melakukan Penelitian di Bidang Sistem Teknologi Informasi. Yogyakarta: Penerbit Andi.

Nazem, F., \& Mozaiini, M. 2014. Investigating the Relationship Between Leadership Style (Transformational and Pragmatic) and Employees' Job involvement at Islamic Azad University of Roudehen, Damavand, Pardis, Boomehen, and Firuzkuh to Provide an Appropriate Model. Bulletin of Environment, Pharmacology and Life Science, 3, p.8288 .

Odumeru dan Ogbonna., 2013. Transformasional vs Transactional Leadership Theories: Evidence in Literature., International Review of Management and Business Research. Vol. 2 Issue. 2 p. $355-361$

Podrug N., Pavicic J., and Bratic V. 2006. Cross-Cultural Comparison of Hofstede,s Dimensions and Decision-Making Style Within CEE Context.

Robbins, P. S., 2007. Organizational Behavior. Organizational Behavior. $12^{\text {ed }}$ ed. New Jersey: Pearson Education.

Rusi Sun and Weijie Wang, 2016, Transformational leadership, employee turnover intention, and actual voluntary turnover in public organizations., Public Management Review Volume

Sekaran, U. and Bougie, R. 2013. Research Methods for Business: A Skill Building Approach, $6^{\text {th }}$ ed. New Jersey: John Wiley \& Sons.

Sheikh, A.Z., Newman, A., and Azzeh, S.A.A. 2013. Transformational Leadership and Job involvement in The Middle East: The Moderating Role of Individually Held Cultural Values, The International Journal of Human Resource Management, 24, 6, p.10771095

Subiyantoro, E. and Hatane, S.E. 2007. Dampak Perubahan Kultur Masyarakat Terhadap Praktik Pengungkapan Laporan Keuangan Perusahaan Publik Di Indonesia. Jurnal Manajemen dan Kewirausahaan, 9, 1, p.18-19.

Thompson, L,L., 2008. Organizational Behavior Today., Pearson Education International Inc., Upper Saddle River, New Jersey

Tiwari S., and Singh, S.K. 2014. Moderation Effect of Job Involvement on the Relationship Between Organizational Commitment and Job Satisfaction. Sage pub.

Treven, S., Mulej, M., and Lynn, M. 2008. The Impact of Culture on Organizational Behavior, Management, 13, 2, p. 27-39.

Tsai, W., Chen, H., and Cheng, J. 2009. 'Employee Positive Moods as a Mediator Linking 
Transformational Leadership and Employee Work Outcomes,' The International Journal of Human Resource Management, 20, 1, p.206-219.

Walumbwa, F.O., Lawler, J.J., and Avolio, B.J. 2007. Leadership, Individual Differences, and Workrelated Attitudes: A Cross-Culture Investigation. Applied Psychology: An International Review, 56, 2, 212-230.

Wu, L. 2011. Beyond Satisfaction,' Managing Service Quality: An International Journal. 21, 3, p. $240-263$.

Yoo, B., Donthu, N., and Lenartowicz, T. 2011. 'Measuring Hofstede's Five Dimensions of Cultural Values at the Individual Level: Development and Validation of CVSCALE,' Journal of International Consumer Marketing, 23, 3-4, 193-210 